\title{
Desafíos regulatorios para la detección y sanción de delitos económicos en chile
}

Christian M. Nino-Moris

Director Académico, Diplomado en Auditoria de Fraude Corporativo, Universidad Alberto Hurtado

Las recientes diligencias investigativas por parte de la Fiscalía en torno a las masivas estafas piramidales, también conocidas como Ponzi Scheme, han reflotado una vieja discusión respecto al rol fiscalizador del regulador financiero. El debate se agudiza ante una evidente limitación de recursos humanos y financieros para hacer frente a estas malas prácticas rentistas, donde su rol se ve truncado ante la ausencia de una tipificación penal que sancione tanto la oferta (réditos exuberantes) como la demanda (inversionistas ávidos del dinero fácil). Este articulo trata de explicar algunas problemáticas subyacentes que fomentan los delitos económicos.

as figuras delictivas de cuello y corbata de las que hemos sido testigos hoy parecieran ser que están a la orden del día; o más bien son las redes sociales las que se han encargado de sacar a la luz prácticas fraudulentas que han sido parte del patrimonio nacional, y que estaban en el más absoluto anonimato. Mientras tanto, el clásico cuento del tío y "pepito paga doble" aún siguen teniendo su "cuota de mercado" a lo largo de la historia de Chile, readecuándose a los tiempos de hoy. Las estafas piramidales también siguen en constante mejora respecto a lo que fue en sus inicios en el año 1920, cuando Carlo Ponzi (Knutson, 2011) se inmortaliza al crear este tipo de engaños financieros. Este exitoso "modelo de negocios" siguen atrayendo a más incautos que, ávidos del dinero fácil, están dispuestos a vulnerar cualquier ley del mercado, y peor aún, a victimizarse de su mala decisión.

Solo a modo de corolario, repasemos nuestra historia en lo que respeta a este tipo de estafas: "La Coneja" en el año 1971; "Cooperativa de Ahorro La Familia" en el año 1975; la Financiera "La Cutufa" el año 1989; Fermex S.A. (los "quesitos mágicos") en el 2006; "La Célula de Concepción" en el 2008; DMC Inversiones en el 2015; y la reciente empresa AC Inversions (El Mercurio, 2016), cuya investigación está en curso de la mano de otras empresas de similar modus operandi. Convengamos en que todos estos esquemas piramidales convergen en lo mismo: funcionan sin regulación ni supervisión directa por alguna entidad fiscalizadora-financiera; ofrecen altas tasas de interés (usura) y, sus beneficiarios no declaran ni un solo peso al Fisco de Chile por sus jugosos gananciales. Asimismo, los negocios piramidales se diferencian de un negocio 
multinivel (Santolalla, 1992 citado en García Grande, 2004) en que aquéllos no pagan impuesto de manera regular por las operaciones que celebran; el capital se "recicla de abajo hacia arriba" (i.e. los primeros en llegar aseguran su retorno con los nuevos participes que se incorporan), los ingresos son el capital que aportan los clientes (y no por la gestión del capital en sí), y ante una "fuga de capitales" la pirámide colapsa, quedando en evidencia la estafa.

Por un momento uno pensaría que Chile se está transformando en un "paraíso de estafas". Efectivamente, existen muchas condiciones favorables para ello: una legislación laxa en términos de la penalidad y tipicidad para quienes se embarcan en delitos económicos masivos; fiscalización-investigativa limitada, y desidia de la población para comprender temas duros, que a la larga es un "debe" del Estado en proporcionar una educación financiera amigable a la comunidad, quizás desde la escolaridad, como ocurre en países desarrollados (el famoso financial literacy)

\section{La importancia de un marco regulatorio adecuado}

Insisto en algo que en el pasado ya había escrito (Nino-Moris, 2015), y es que, si observamos con detenimiento los casos de estafas y fraudes en Chile, podemos sostener que hemos avanzado más en tipificar o reforzar aquellos fraudes contable-financieros desde la perspectiva del empleado -los que se cometen "en contra de la organización" (sean con o sin fines de lucro)- que en aquellos cometidos "en favor de la organización". En otras palabras: aún no están claramente tipificados los fraudes contable-financieros en los que participan o involucran los altos directivos y ejecutivos que conforman el Gobierno Corporativo (u el órgano directivo superior) de una organización, con prescindencia de su tamaño. De hecho, si se repara tanto en la Ley del Mercado de Valores (LMV, 2016), como en la Ley de Sociedades Anónimas (LSA, 2016), ninguna de ellas - a pesar de los más de 30 delitos de "cuello y corbata" que resultan de esas leyes- se refiere a aspectos de la contabilidad fraudulenta tales como ocultamiento, mutilación, destrucción, o alteración de los registros contables (todo esto, al margen de la existencia del artículo 97 del Código Tributario). Por otro lado, parece oportuno decir que el último listado de grandes contribuyentes, enunciados en la Resolución Exenta 119 del Servicio de Impuestos Internos (SII, 2015), no sea parte del escrutinio público por parte de algunas de las superintendencias existentes (obviamente en aquellos casos que no lo están); incluso, no siendo forzosamente"agentes de valores emisores de instrumentos de oferta pública". La gran mayoría de estas grandes empresas no están siendo auditadas bajo ninguna circunstancia de manera independiente. Peor es el escenario que enfrentan las Pymes, donde las defraudaciones van a en ambas direcciones, empleado-empleador, y que son "pan de cada día".

Si el lector repasa las notas periodísticas de la época, advertirá lo complejo que fue para la Fiscalía perseguir el caso Fermex S.A. ("los quesitos mágicos") (Fiscalía, 2008) debido justamente al vacío legal existente en asociar la estafa piramidal con algún tipo legal establecido. Aquí sale a relucir la destreza y "chispeza" tanto de los abogados querellantes, como de los fiscales prosecutores del delito. Aquí debutan figuras penales tales como la estafa, la apropiación indebida, la asociación ilícita, el lavado de dinero, la evasión tributaria, entre otras. Finalmente, tuvieron que pasar muchos años para llegar a una salida judicial, que afloró el año recién pasado.

\section{Un inadecuado alcance al bien jurídico protegido}

Aquí una explicación a este particular "fenómeno". Existe una corriente de eruditos que pregona que no sería pertinente una legislación "paralela" respecto a las cuestiones de persecución penal en lo tocante a los "delitos contable-financieros" debido a que ya el Código Tributario se hace cargo de tales aspectos en su artículo 97. El problema en defender esta "tesis" está plasmado en dos preguntas. ¿Cuál es el bien jurídico protegido en el delito de "estafa contable"? ¿Cuál es el bien jurídico protegido por la ley tributaria? Para el primero, existe un consenso mayoritario en que lo que se protege es el patrimonio (Balmaceda, 2012); en el segundo, lo que se protege es el Erario Fiscal (cumplimento de la obligación de pagar los impuestos). Por tanto, cuando se persiguen delitos de estafa en donde los afectados son los particulares, en lugar de defender penalmente el patrimonio privado, las causas terminan defendiendo el patrimonio fiscal (invocando con fuerza el articulo 97 número 4). Dicho de otro modo, parece inadecuado pretender "proteger" el interés de los inversionistas (especialmente minoritarios) al amparo de las leyes tributarias -que en la práctica no los protege- en donde los objetivos que se persiguen son totalmente diametrales. En suma, no hay un "espejo" sancionatorio en nuestro mercado de capitales que castigue de forma clara las manipulaciones y fraudes contablefinancieros -como si lo es por ejemplo en el Perú-, razón por la que muchas causas derivan en sanciones penales tributarias solamente. Un ejemplo de esto han sido los casos emblemáticos Juan Pablo Dávila-Codelco e Inverlink, y otros tantos casos en que no llegan a tener una connotación pública (CDH, 2016). 
La legislación chilena no se define lo que es fraude, tampoco se define lo que es un "delito económico", y peor aún, nuestro Código Penal no se hace cargo en definir qué es una estafa. Esto ha dificultado la persecución de estratagemas como las de tipo piramidal. En contraste, países de la región como Perú, Colombia, Ecuador y México, han incorporado este tipo de estafa a su lista de delitos (Congreso, 2016). Lo anterior, evidencia lo atrasado que estamos cuando se trata de legislar sobre delitos de cuello y corbata. Paradójicamente, países desarrollados están dando un giro hacia una nueva rama del Derecho que aborda los aspectos puramente contable-financieros como una rama especializada, y no circunscrita a la cuestión tributaria, o al amparo del Derecho Comercial (Código de Comercio), esto a propósito de la sofisticación y proliferación a nivel mundial de las ultimas normas internacionales de información financiera, NIIF o IFRS, y la creciente tendencia hacia el compliance corporativo.

\section{Prácticas contables inadecuadas y la experiencia internacional}

Refuerza lo anterior, en que existe una visión limitada sobre la naturaleza del fraude, con una comprensión solo referida a "meter las manos a la caja" o "arrancarse con el dinero", olvidándonos que las legislaciones de muchos países consideran incluso aspectos "no monetarios". Por ejemplo, se citan algunas prácticas contables prohibidas (y con severas sanciones) que aborda la legislación estadounidense (para quienes adoran todo aquello que provenga de "Tío Sam"): hechos económicos sin registro en los libros contables (Offthe-book accounting); manipulación de provisiones contables (cookie Jar \& big bath accounting); omisión en revelar información relevante al mercado (lack of disclosure); ventas inducidas hacia los canales de distribución (channel stuffing), operaciones con fecha retroactiva (backdating). Como se aprecia, el entorno norteamericano penaliza cualquier manifestación de contabilidad creativa nociva (Anderson, 2002). Por tanto, son perfectamente admisibles como delitos contable-financieros aquellos que dicen relación con "adulterar"y"ocultar" algún aspecto sobre los estados financieros de una entidad. Mientras tanto en Chile, seguimos permitiendo la "importación" de nuevas formas de defraudación, y que siguen "bypasseando" al regulador financiero; o al menos, la respuesta legislativa no está respondiendo a la velocidad de nuevas figuras delictivas.

\section{Fair presentation versus compliance tributario}

En consideración de lo antes expuesto, el problema se agudiza aún más por la creciente legitimización de la "contabilidad tributaria" (con abismante devoción al SII), la cual le ha hecho un flaco favor a la institucionalidad del mercado financiero nacional. Lo más frustrante es que se ha instalado la idea de que un régimen contable-tributario es una "opción más válida" que un régimen contable-financiero.

Esto ha permeado a tal magnitud que incluso algunos peritos contables, en la evacuación de sus informes periciales, llegan a conclusiones sobre hechos en controversia de manera sesgada. Ellos muchas veces dictaminan sólo desde la óptica de la "contabilidad tributaria", sin siquiera reparar ni dimensionar las implicancias que denota el omitir aspectos de la "contabilidad financiera". Esta última, es (o debiese ser) la única contabilidad oficial de un negocio según la Ley 13011/58, de la cual se sirven otros "stakeholders", tales como bancos, empresas contratistas, empresas de factoring, la inspección del trabajo, etc. Entonces, volvemos a lo mismo: el mercado no sanciona a aquellas empresas que no llevan contabilidad financiera adecuadamente. Esto nos obliga a recurrir a las normas tributarias para lograr una sanción, pero de manera sesgada. Si es el Fisco de Chile el afectado por el no pago de impuestos, allí si existe un gran problema. Sin embargo, si el afectado es un accionista minoritario (incluso una Pyme), en donde su gerente manipuló las cifras contables de la sociedad, el problema se torna un drama. Ese accionista deberá recorrer ese largo periplo de figuras penales y demandas civiles que no necesariamente terminarán en una compensación. Me parece que esta situación no es justa.

\section{Recomendaciones}

El caso ENRON, Worldcom y Bernard Madoff son una muestra de lo serio que es engañar al mercado en EEUU. Madoff fue sentenciado a 150 años de cárcel en el año 2009 por enriquecimiento ilícito mediante el uso de un "exitoso" esquema piramidal. Entonces, no hay que darle muchas vueltas al asunto. Si se trata de imitar lo bueno, procedamos entonces como la Ley Sarbanes-Oxley, SOX/2002 de Estados Unidos, que en su sección 906 y 1102 sanciona con cárcel de 10 a 20 años, y con multas de un millón a cinco millones de dólares para aquel ejecutivo que altere, destruya, mutile o esconde un registro contable-financiero.

Una vía practica para incorporar algunas de las buenas prácticas de la Ley SOX en nuestra legislación, seria, por ejemplo, incorporar un artículo 134bis al título XIV de la Ley de Sociedades Anónimas, con medidas sancionatorias similares al entorno estadounidenses o australiano. ¿Es muy complejo de poner en marcha dicha modificación legal? La supremacía de la realidad sugiere que 
debería ser de fácil tramitación legislativa. Sin embargo, la tecnocracia es superada por la voluntad política de turno que impide alcanzar los anhelados acuerdos (i.e. votos), como para materializar este tipo de iniciativas, debido principalmente, a la fuerte concentración del poder económico y político en un grupo reducido de personas.

\section{Conclusión}

A pesar de nuestra larga historia de estafas piramidales, el caso AC Inversions nos recuerda que nada se ha hecho desde el punto de vista legislativo para fortalecer la detección y sanción de delitos económicos en Chile. Esperemos que prospere el proyecto de ley sobre las estafas piramidales, cuyo objetivo es permitir que las empresas con una estructura de negocios tipo piramidal, sean fiscalizadas por la Superintendencia deValores y Seguros, SVS. Asimismo, con el advenimiento de las NIIF/IFRS, se hace imperioso que ciertas prácticas contablefinancieras de carácter fraudulento sean reconocidas en nuestra legislación penal. La complejidad de estas normas y el creciente dinamismo en la práctica de los negocios, han forzado naturalmente a que los países emigren hacia una nueva institucionalidad llamada Derecho Contable. Esto confirma la importancia de la información financiera como el lenguaje universal de los negocios en la era moderna.

\section{Referencias}

Aguirre, B. \& V. Ibarra, 15 interrogantes sobre AC Inversiones, el caso que remece al sistema financiero local. 2016. El Mercurio, Economía y Negocios, Santiago, Chile, 6 mar., último acceso 16/07/2016: http:// www.economiaynegocios.cl/ noticias/noticias.asp?id=231784

ANDERSON, S. 2002. Earnings Management and "Creative Accounting" Activities. Davis Graham \& Stubbs LLP, Disclosure Practices Update. Jan 30, 2002. pp1-14

BALMACEDA, G. 2012. El Delito de Estafa, Doctrina y Jurisprudencia. $1^{\text {a }}$ ed. Santiago, Thomson Reuters, p13.

$\mathrm{CDH}$. Centro de Derechos Humanos. sf. Registro de Casos de Corrupción 1998-2008. Facultad de Derecho, Universidad de Chile, último acceso 16/07/2016:

http://www.cdh.uchile.cl/ corrupcion/pdf/Casos_Chile.pdf

CONGRESO. Cámara de Diputados. 2016. Modifica el Código Penal con el objeto de agravar la pena aplicable al delito de estafa en caso de que afecte a una pluralidad de sujetos. Boletín número 10622-07, Sesión 14, Legislatura 364. Abril 19.
FISCALÍA. 2008. Caso Fermex: la"Estafa de los Quesitos". Una exitosa experiencia de protección y reparación de las víctimas de delitos patrimoniales. Revista Jurídica del Ministerio Público 34(1): 291-297.

KNUTSON,C.2011.The RemarkableCriminal Financial Career of Charles Ponzi. Pp1-30, último acceso 16/07/2016: http://www.mark-knutson.com/blog/ LMV. Ley del Mercado de Valores, $N^{\circ} 18045$. Diario Oficial de la República de Chile, Santiago, Chile, 22 de octubre de 1981.

LSA. Ley de Sociedades Anónimas, N¹8046. Diario Oficial de la República de Chile, Santiago, Chile, 22 de octubre de 1981.

NINO-MORIS, Ch. 2015. Caso Penta: una estocada al jaguar chileno. Análisis \& Opinión, América Economía, ultimo acceso 16/07/2016:

http://www.americaeconomia.com/ analisis-opinion/caso-penta-unaestocada-al-jaguar-chileno-0

SANTOLALLA, J. R. 1992. Diferencias entre Venta Piramidal y el Marketing Multinivel, citado en "Marketing Multinivel", María Dolores García Grande. Editorial ESIC Marketing \& Business School, 2004. p53.

SII. Servicio de Impuestos Internos. 2015. Resolución Ex. 119: Fija Nómina de Grandes Contribuyentes. Dirección de GrandesContribuyentes, diciembre2015.

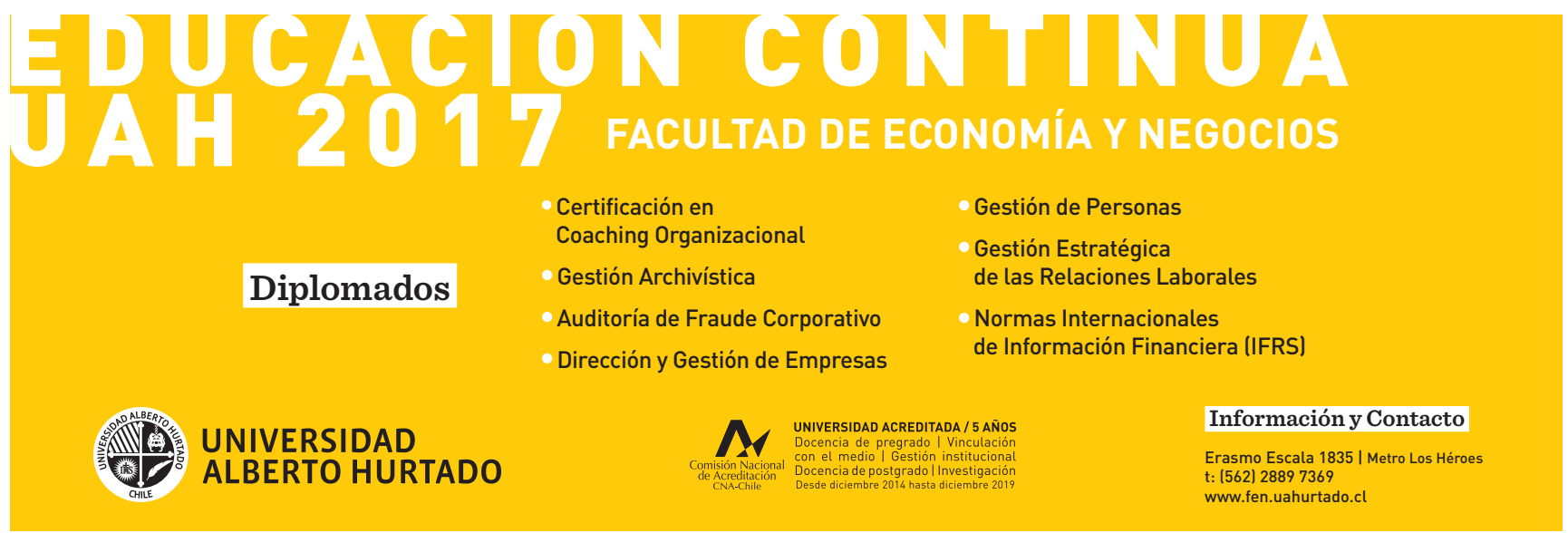

